\title{
SUSTAINABILITY AND. ECO PRACTICES IN TOURISM
}

\section{Robinet Jacob*}

Tourism is one of the greatest successful business activities in the world. Its success depends upon the success of a number of other sectors. The tourism industry doesn't manage the majority of products and experiences it sells. Tourism managers are transporting people to view natural features, cultural attractions, economic activities and lifestyles of people worldwide. Unlike other enterprises, tourism takes consumers to the product, not the products to the consumers.

Along with the tourism growth there have been so many problems too. They include deterioration of so many destinations, environmental degradation, increasing hostility of residents in certain destinations, change in local cultures etc. Tourism occurs in environments, which have limits. By violating these limits serious and irreversible damage has occurred in various destinations, which ultimately affects tourism development. The tourism industry is vulnerable to changes in the natural environment as well as to the cultural environment. Many destinations are popular due to local cultural traditions of the hosts. Tourist arrivals in a big way may result in violation of local traditions and community standards. Mass tourism can entirely change the character of a community. The close relationship of tourism between environment and local culture and the importance of sustainable tourism development planning are becoming increasingly recognized.

\footnotetext{
* Head of Tourism, Pazassi Raj College, Pulpally P.O., Wayanad Dist., Kerala.
} 


\section{The Concept of Sustainable Development}

The concept of sustainable development emerged as a result of increasing concern on environmental problems, depleting natural resources and increasing poverty in the 1980's. The concept has developed through various United Nations Conferences. The World Tourism Organization's sustainable Tourism initiatives focus on greater understanding of the carrying capacity of tourism destinations and tools called environmental indicators that can provide information on the healthiness and viability of destinations. Harmonious relationship between tourism and the natural and socio-cultural environments is required for sustainable tourism. The term 'sustainable' means permanence. This conveys the message of maximum use of resources without creating any harm to the natural and socio-cultural environments. It deals with development that has been carefully planned and managed. Sustainable tourism was defined by the Globe' 90 conference on sustainable development as the management of tourism resource in such a way that fulfill economic, social and aesthetic needs while maintaining cultural integrity, essential ecological processes, biological diversity and life support systems. The Manila declaration of World Tourism Organization (WTO) held in 1980, emphasized the importance of both natural and cultural resources in tourism and the need for conservation of these resources for the benefit of local residents and tourism industry. It states, "the protection, enhancement and improvement of the various components of man's environment are among the fundamental conditions for the harmonious development of tourism. Similarly rational management of tourism may contribute to a larger extent to protecting and developing the physical environment and the cultural heritage, as well-as improving the quality of life". The term sustainable development became popular after the release of Brundtland report in 1987. According to it, sustainable tourism can be defined as tourism that meet the needs of the current generation without compromising the ability of future generations to meet their own demands.

Earlier sustainable tourism was widely considered as equivalent to alternative tourism. Now a days, the term sustainability is used in relation with the wide spectrum of tourism activity. Tourism activity as a whole cannot be sustainable, if mass tourism is not made sustainable. Mass tourism commenced only in 1920's, firstly in USA when mass production of vehicles was started. It grew in 1930's when the system of paid holidays was introduced. International tourism continues to grow as it has the ability to invent new resources. This happens due to the world society's mounting leisure needs. 


\section{Various Issues}

Many underdeveloped countries started promoting international tourism without developing sufficient infrastructure and taking precautions. Many of them transformed into service oriented tourist economies from rural based economies without passing through the intermediate phase of industrialization. The social impact of tourism also varies from one society to another. Tourism promotes the standard of living of local people, foster international understanding and preserve cultural heritage. But it creates social tensions, distortion of life styles and social decay in some societies. Tourism activity is to a certain extent, self destructive as it destroys the resource that feeds it. The natural environment is always affected as a result of increase in the number of tourists. The unsustainable effects are in the form of economic, social, environmental and political fronts. Sustainable tourism can be assessed in different ways. In ecological terms it means that the level of tourism and tourist activities has to be compatible with the maintenance and enhancement of ecological balance, biological resources and their diversity so that the capacity of the environment to regenerate itself is not impaired. In social and cultural terms, sustainable tourism development needs to ensure that it is compatible with the culture and values of the people, that its benefits are shared and that it strengthens community identity, promotes wider participation in decision making and enhances peop!e's control over their own lives. In economic terms sustainable tourism development needs to facilitate a process of development that is economically efficient, has positive backward and forward linkages that relieve pressure on fragile resources and allows and promotes management of resources in ways that not only support present needs but which can also support the needs and aspirations of future generations. Essentially tourism which can be sustained over the long term, because it does not result in negative consequences for the social, cultural and physical environments of the area in which it takes place.

\section{Environmental Indicators and Significance of Carrying Capacities}

The World Tourism Organization's [WTO] sustainable tourism initiative focus on greater understanding of the carrying capacity of tourism destination and tools called environmental indicators that can provide information on the healthiness and viability of destinations. It is to devise simple measures of environmental sensibility, stress on the environment, results of tourism activity and the human and biological consequences of tourism activity. 
Table I. Core indicators of sustainable tourism:

\begin{tabular}{|c|c|}
\hline Indicator & Specific Measures \\
\hline 1. Site protection & Category of protection according to IUCN index. \\
\hline 2. Stress & $\begin{array}{l}\text { Tourist numbers visiting site [per annum/peak } \\
\text { month]. }\end{array}$ \\
\hline 3. Use Intensity & Intensity of use-[ peak persons/hectares] \\
\hline 4. Social Impact & Ratio of tourists to locals [peak period] \\
\hline 5. Developing Control & $\begin{array}{l}\text { Existence of environmental review procedure } \\
\text { or formal control over development of site } \\
\text { and use densities. }\end{array}$ \\
\hline 6. Waste Management & $\begin{array}{l}\text { Percentage of sewage from site receiving } \\
\text { treatment [additional indicators may include } \\
\text { structural limits of other infrastructural } \\
\text { Capacity on site eg: water supply, garbage]. }\end{array}$ \\
\hline 7. Planning process & $\begin{array}{l}\text { Existence of organized regional plan for } \\
\text { Tourist destination region [including tourism } \\
\text { Component]. }\end{array}$ \\
\hline 8. Critical Ecosystems & Number of rare /endangered species \\
\hline 9. Consumer Satisfaction & $\begin{array}{l}\text { Level of satisfaction of visitors } \\
\text { [Questionnaire based] }\end{array}$ \\
\hline 10. Local Satisfaction & $\begin{array}{l}\text { Level of satisfaction by locals } \\
\text { [Questionnaire based]. }\end{array}$ \\
\hline
\end{tabular}

*IUCN-International Union for the Conservation of Nature and Natural resources Source: WTO [1995], Madrid.

A concept, which is fundamental to the management of sustainable tourism, is 'carrying capacity'. Carrying capacity analysis is the most reliable and effective method for sustainable tourism development. Carrying capacity refers to the level of visitor use, an area can accommodate with levels of satisfaction for visitors pertaining to few impacts on resources. Carrying capacity represents the point beyond which the tourism industry in any destination becomes unsustainable. In tourism, assessing carrying capacity is really a complex task as a variety of products and services are coming from the same environment. Carrying capacity involves several elements like the physical, ecological and cultural carrying capacity levels. The fundamental question is about the number of tourists that can be put in a destination without threatening the long-term viability of the 
system. When dealing with assessing the above factors, we have to consider the following factors too.

- The impact of human activity on a system may be gradual and may affect different parts of the system at different rates.

- Tourism depends on many aspects of an environment-wildlife, aesthetics, access to shoreline etc. Each has its own response to different levels of use.

- All tourism environments are multipurpose environments. The other uses must also be considered in determining the correct level of tourism use. In one site, it may not be a matter if a river is diverted or a dam is constructed. But it may have a critical impact on other places, where people downstream depend on it for water or food.

- Different local cultures have different levels of sensitivity to change.

\section{Assessing Carrying Capacities}

Carrying capacity analysis is the most effective method for sustainable tourism development. Inskeep emphasized the importance of carrying capacity in 1991. According to him, there is a need to determine the carrying capacity of a destination so that tourism development

a. Does not result in serious environmental problems such as air, water, noise or visual pollution, congestion, degradation of ecosystems or overload of the infrastructure.

b. Does not result in a loss of cultural identity of the host society or social problems, such as crimes.

c. Does not create serious economic distortions, while still bringing economic benefits and maintains tourist satisfaction levels so that the desired tourist market continue visiting the area.

Carrying capacity is defined as the level of tourist presence, which creates impacts on the host community, environment and economy that are acceptable to both hosts and tourists and sustainable over future time periods. The impact of tourism on many destinations will be divided by a wide variety of factors like

a. the volume of tourist arrivals.

b. the types of tourism activity. 
c. the fragility of local environment.

d. the difference in socio-cultural characteristics between the hosts and the tourists.

e. the nature of the host economy.

Many factors are involved in determining the carrying capacity level of a destination. The social infrastructure of a big city may absorb and tolerate more tourists than small islands like Maldives. The cultural characteristics of a destination are also having an important role in determining impact. The more unusual the cultural background, the more attractive the destination may become, but the more likely it to be affected by the presence of tourists. The result will be commercialization of local features and traditions. The environment will be changed by the presence of tourists. The degradation of environment can occur through poorly planned ad hoc development. The economic structure of a society will determine the benefits and costs associated with tourism. Developed economies are able to secure maximum benefits from tourism by incurring the minimum costs. The availability of local resources like land, labour, capital etc will also have a major influence in tourism development. Tourism development may result in improved infrastructure, which will be available to hosts and tourists and will enhance the quality of life of the local people. The political structure reflects the ideals and beliefs of the local people and can actively encourage tourism development or hinder it. These local factors have a significant say in tourism development and in assessing impacts and carrying capacity.

Some other alien factors like tourist characteristics and the nature of tourism activity are also important in determining the social and cultural impact of tourism on the host community. Mass tourists Interact more with the local people than other groups and are not ready to adapt to the local norms and customs. The greater the difference between the tourist's and local's social and cultural background, the greater the impact. Other tourist characteristics like visitor expenditure patterns, mode of transport, size of the group, age, educational background, income and purpose of visit will influence the magnitude of the impact in the host society. The types of tourism activity is also linked with the above factor. The presence of certain activities like gambling, prostitution, drugs etc can bring social impacts with far reaching consequences. Thus carrying capacity relates to how much tourist presence and local factor change the visitor is prepared to tolerate. 


\section{The Carrying Capacity Studies}

WTO conducted a carrying capacity study of Goa in 1989. It included an assessment of the social and environmental impacts of tourism and guidelines for the planning, development and control of tourism. For assessing the carrying capacity, the beaches and their adjacent lands along with labour supply capabilities, infrastructure capacities and social impacts were considered. The study assessed that an average density of 40 square meters of beach area per tourist bed would be appropriate for calculating beach carrying capacity. Assuming an average width of sandy beach of 40 metres, application of this density standard means that not more than one tourist bed per one meter of beach frontage should be developed. Also it was decided that not more than 70 percent of the beach or 46 out of the $65 \mathrm{~km}$ of total beach length should be developed. Application of the standard of one meter of beach frontage per tourist bed to 46 kilometres results in an overall regional maximum development level of 46,000 tourist beds. As 30 percent of beds of lower rate levels are expected to be constructed in places directly facing the beach and sea, not more than $35 \mathrm{~km}$ of beach frontage are expected to be actually utilized for development. Based on the 46,000-tourist bed figure, the study projects that some 4.1 million annual tourist arrivals could be received at the optimum development level.

Based on the assumptions of direct employee requirements of one employee per bed in the higher quality hotels and 0.4 employees per bed in the lower quality units, there would be an accommodation employment demand for 28,000 persons. With the addition of employment required in other tourist facilities and services, 60,000 persons would be needed in direct tourism employment while a greater number in jobs indirectly related to tourism. The study also evaluated the social impact of the projected level of tourism development.

\section{Alternative Forms of Tourism and Sustainable Development}

The Tourism private sector has developed some environmentally sustainable tourism ventures especially in the south Indian states of Kerala, Tamil Nadu and Karnataka. The Thenmala ecotourism project in the Kollam district of Kerala is an example. The concept of sustainable tourism development has received much emphasis internationally since the 1980's. The process of sustainable tourism has already started in Andamans and Lakshadweep islands where it is planned to have a high value low volume tourist traffic to certain selected islands. More 
studies are needed to assess the impact and carrying capacity of the emerging destinations.

Maldives situated in the Indian Ocean favors the development of a selective luxury tourism activity on segregated islands close to the international airports. Maldives consists of almost 1200 coral islands and a total area of about $300 \mathrm{sq} . \mathrm{km}$. They are receiving around 2 lakh tourists per year. Maldives has about 70 resort islands with more than 7000 beds. There is one hotel on in most of the resort islands. As a result of the growing number of tourists, the government has to deal with the waste disposal problem and destruction of reefs. Huge consumption of drinking water resulted in the need for seawater desalination. Visitors were asked to take back the plastic litter with them on their flight back. Use of eco bags were made common. A ceiling on construction of new guesthouses is another step. To minimize the embarrassing cultural impact of visitors on the island people and the traditions, tourist resorts are constructed on uninhabited islands. The contact between tourists and local population is limited to male service staff and organized excursions to some villages. Although the measures taken, conforms to the principles of sustainable tourism, they are expensive to a certain extent.

Another best example for serious sustainable tourism activity is the adventurous trekking program named 'the Periyar tiger trail', which is conducted in the Periyar tiger reserve of Kerala. This project has been conceived and developed by Kerala forest department with the ex-vayana bark collector's Eco Development Committee as a participatory eco-tourism project. These ex-vayana bark collectors were former inhabitants of forests and were involved in illegal trading of forest goods. Constant interaction of forest officials with the poachers transformed them to conservationists. Their intimate knowledge about the plants and the movement of animals makes them successful guides. Conservation efforts had a double effect when the habitual offenders were earnestly involved in the participatory eco tourism strategy. To reduce human impact on the eco system, only a maximum number of 20 trekkers will be allowed to participate in the program every week as the trekking trail passes through the heart of the sanctuary. Guides, who are reformed poachers, will lead trekking groups. Armed forest guards with state of the art communication facilities, geared to face any emergency situation will be escorting the whole group all through the trek. The achievements are so remarkable that during the last two years 23 individuals were caught attempting to poach wildlife and another 18 have been penalized for cutting sandalwood trees and other plants from the reserve. The hard-core eco offenders, who were a constant threat to the Periyar tiger reserve, were brought into the main stream of the society. It helped them in finding out a good alternative source of income. 
The social ostracism to the former poachers was absolutely removed. Their role reversal is preventing other habitual offenders from destroying the forest and is now associating with conservation efforts.

\section{Eco Practices in Tourism: The Kerala Model}

Tourism industry consists of so many sub-sectors like hospitality industry, tour operation business, travel agency business etc. Eco friendly practices are required for each sub sector for the industry to become sustainable. Kerala tourism has launched a unique Eco certification scheme which is a set of practices for each sub sector to become eco friendly and is named as Eco initiative- (Eco-Kerala). Its objectives are

1. To convert the entire tourism industry in Kerala into eco-friendly mode.

2. To strengthen Eco tourism development initiatives in the state.

3. To ensure local community involvement in tourism initiatives leading to employment generation and income augmentation.

4. To create public awareness and involvement in responsible tourism development.

This programme has already been initiated for the hospitality industry, which provides different certificates like Ordinary member, Club member and Diamond member on the basis of the fulfillment of certain conditions specified.

Through sustainable tourism development, the natural, cultural and other resources can be conserved for future. Tourism destinations developed on the basis of the principle of sustainability can conserve the area's natural and cultural resources. Thus it can act as a tool for conservation of environment. Community based tourism giving importance to generation of benefits to local communities is another important facet of sustainable development. The quality tourism approach related to sustainable development, which protects tourism resources and attract the kinds of tourists who will respect the local culture and traditions, is the need of the hour. The concept of sustainable development shall be included in the tourism planning development and management process. 


\section{References}

1 World Tourism Organization (1995), National and Regional Tourism planning, Routledge, London.

2 Kumar Ravibhushan (1995), Coastal Tourism and Environment, APH Publishing Corporation, New Delhi.

3 Holloway, Christopher (1994), The Business of Tourism, Pitman publishing London.

4 Cooper Chris, Fletcher, John Gilbert, John Wanhill, Stephen(1994), Tourism Principles and Practice, Pitman Publishing, London.

5 Sinha P.C. (1997), International Encyclopaedia of Tourism Management, volume 2, Ammol Publications New Delhi.

6 Sharma J.K. (2000), Tourism Planning and Development, ANew Perspective, Kanishka Publishers, New Delhi.

7 Gupta, Sunil, Bansal S.P. (198) Tourism towards $27^{\text {st }}$ century, Deep and Deep Publications, New Delhi.

8 Sharma J.K (2000). Tourism and Development Design for Ecological Sustainability, Kanishka Publishers, New Delhi.

9 Bagri S.C (2003), Trends in Tourism promotion-Emerging Issues, Bishen Singh Mahendra Pal Singh publishers and Distributors, Dehradun.

10 Sethi, Praveen(1999), Handbook of Sustainable Tourism, Anmol Publications Ltd, New Delhi.

11 Eco-Guidelines for Hospitality sector in Kerala, Kerala Tourism, 2004. 